\title{
Integration of E-education and Knowledge Management
}

\author{
Liyong Wan ${ }^{\mathrm{l}}$, Chengling $\mathrm{Zhao}^{2}$, and Wei Guo ${ }^{2}$ \\ 1 College of Humanity and Social Science, Wuhan University of Science \\ and Engineering, Wuhan,China,wanliyongccnu@yahoo.com.cn \\ 2 Department of Inforamtion Techonology, Central China Normal \\ Universtiy, Wuhan,China
}

\begin{abstract}
With the realization that knowledge is a core resource, organizations are now attempting to manage knowledge in a more systematic and more effective way. However, managing knowledge is not always an easy task. In particular contexts, such as online e-education, knowledge is distributed across both time and space and may be constrained by social, cultural and language differences. This paper demonstrated the common characters of knowledge management and e-education, and proposed the current potential problems in e-education. The authors tried to develop a set of guidelines to help overcome problems using tools and techniques from $\mathrm{KM}$, they proposed three strategies: corporate explicit knowledge and tacit knowledge; use the theory of $\mathrm{KM}$ to guide e-education resource management; use the theory of $\mathrm{KM}$ to guide eeducation resource management. These strategies will help us to develop a better e-education framework.
\end{abstract}

\section{Introduction}

The term "Knowledge Management" (KM) is used to describe everything from the application of new technology to the harnessing of the intellectual capital of an organization (Sallis and Jones, 2002). It is not one single discipline; rather, it is an integration of numerous endeavors and fields of study. In brief, $\mathrm{KM}$ is the management of processes that govern the creation, dissemination, and utilization of knowledge by merging technologies, organizational structures and people to create the most effective learning, problem solving, and decision-making in an organization $[1,2]$.

In the recent years a wide range of business techniques, including performance management, quality assurance and total quality management, have had a direct or indirect impact on education, and $\mathrm{KM}$ is set to do the same $\mathrm{KM}$ should have a

\footnotetext{
Please use the following fornat when citing this chapter:
}

Wan, L., 7hao, C.. Guo, W., 2007, in IFIP International Fedcration for Information Processing, Volune 252, Integration and Innovation Orient to F-Socicty Volume 2, eds. Wang, W.. (Boston: Springer), pp. 453-459. 
resonance in education, as one major function of education is the imparting of knowledge. This implies that just as businesses attempt to improve the efficiency and effectiveness of their operations through $\mathrm{KM}$, so educational institutions could use the potential of $\mathrm{KM}$ to enhance the learning of students. We can see that $\mathrm{KM}$ and online e-education share some common elements.

The first is community. From KM perspectives, the concept of communities is essential because knowledge in an organization is often built up and generated by small, informal, self-organizing network of practitioners. In e-education, community is regarded as the model for dynamic, productive knowledge creation and sharing in education. The second is collaboration. Most organizations realize that they will improve performance if their staffs work together. Tools such as e-mail and intranets are also used to encourage active collaboration among people in organization. Collaboration is one of the most critical issues in educational context, especially in online e-education where people and knowledge are distributed across time and space [2].

\section{Knowledge Management strategies}

An effective $\mathrm{KM}$ initiative requires the combination of the three strategies: the utilization of both explicit and tacit knowledge, the promotion of knowledge creation and sharing at all levels, and the application of the right mix of KM tools and techniques.

\subsection{Knowledge Management Process}

In some ways, educational systems are like knowledge management (KM) systems; both involve the creation of useful knowledge from information or data found in available resources. Knowledge management is a "system and managerial approach to collecting, processing and organizing enterprise-specific knowledge assets". Accenture views knowledge management functions as a six-step process: (1) acquire, (2) create, (3) synthesize, (4) share, (5) use to achieve organizational goals, and (6) establish an environment conducive to knowledge sharing. Ernst and Young promote a 4-phase KM approach: (1) knowledge generation, (2) knowledge representation, (3) knowledge codification, and (4) knowledge application. Not surprisingly, there are some similarities between Kuhlthau's information search process and these KM models.

\subsection{Knowledge Conversion}

According to Nonaka (1991), tacit and explicit knowledge are not totally separate but mutually complementary entities. They interact with each other in the creative activities of human beings. Nonaka calls the interaction of these two forms of knowledge, the "knowledge conversion" process. This conversion process is composed of four steps: socialization, externalization, combination, and 
internalization. The first step, "socialization", transfers tacit knowledge between individuals through observation, imitation and practice. In the next step, "externalization", triggered by dialogue or collective reflection, relies on analogy and metaphor to translate this collective tacit knowledge into documents and procedures. "Combination", consequently, reconfigures bodies of explicit knowledge through sorting, adding, combining, and categorizing processes, and spreads it throughout an organization. Lastly, "internalization" Translates explicit knowledge into individual tacit knowledge. $[1,2]$

\subsection{Combination of Tools and Technologies}

Technology can support collaborative work and interaction among individuals within the community in which knowledge creation and sharing takes place. E-mail, groupware, and computer networks are commonly used to connect people with a need to share knowledge over a distance. However, while it is true that no modern organization can manage its knowledge without technology, it is only a part of the equation [2].

\section{The Potential Problems in E-education}

\subsection{The Lack of Human Interaction}

Learning tasks and activities are an important characteristic of good instructional design. Engaging learners and actively involving them in the learning process often increases motivation and learning gain.[3] To be successfully re-used for learning information chunks need to be embedded in interactive learning activities. In order to solve the problems, technologies such as video conferencing, MUDs and MOOs, have been used to create a 'telepresence' or a 'virtual presence'. [2]Nonetheless, people in so-called virtual teams still find that collaborative work is most effective when performed in face-to-face meetings where the issue of trust and ambiguity that surrounds identity in the virtual world are most easily overcome.

\subsection{Problem of Trust}

Trust is at the heart of collaboration. However, communication and social interaction in an online community can present a serious challenge to the existence of trust. From KM perspectives, personal contact and trust are intimately related. Good relations among people in community purge the process of distrust and fear, and break down personal and organizational barriers. Through well-established relationships, people develop the sense of trust, identity and commitment that allows them to create new knowledge and share that knowledge to other people in the community. [2] 


\subsection{Problem of Context Neglect}

Situated learning approaches developed mainly at the end of the $1980 \mathrm{~s}$ emphasize that a human's tasks always depend on the situation they are performed in, i.e., they are influenced by the characteristics and relationships of the context. Because of the relation between cognition and context, knowledge and the cognitive activities meant to create, adapt, and restructure the knowledge can't be seen as isolated psychological products - they all depend on the situation in which they take place. [3]

E-education solutions often do not consider that corporate learning takes place in an organizational context and that learning goals are based on real-world needs [3]. Secondly, many e-education approaches neglect the fact that the delivery of information chunks does not necessarily mean that the user acquires new knowledge. In particular, if the individual's context and characteristics are ignored, learning might not take place at all.

\section{Integration of E-education and Knowledge Management}

Based on the common characters of KM and e-education, we can use some theory and technique of KM to solve the potential problems in e-education, and can also optimize some aspects of e-education.

\subsection{Corporate Explicit Knowledge and Tacit Knowledge}

In e-education, knowledge can also be divided into explicit knowledge and tacit knowledge. Explicit knowledge refers to the knowledge which can be expressed by strict data, formula, axiom and text, easy to be stored and conveyed, such as subject knowledge. Tacit knowledge refers to the knowledge based on personal experiences and several invisible factors, such as personal faith, conception, intuition and power of observation. Tacit knowledge is a kind of knowledge which is hard to express, describe, communicate and share. Explicit knowledge can be delivered in the form of E-mail, CD-ROM and text, and can also be stored in knowledge libraries to be accessed and used in any time. Tacit knowledge can only be manifested by experience sharing among different individuals. We corporate the model of knowledge translation into e-education, the flow process is as follows: [1]

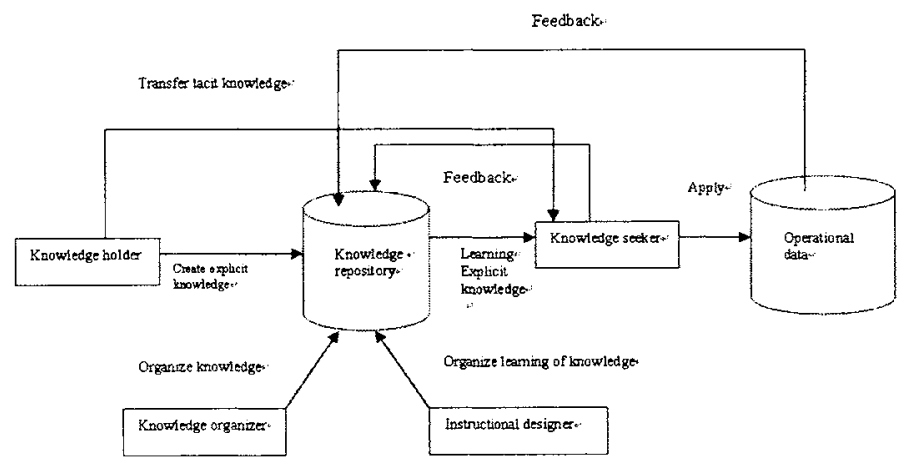


Fig. 1. Corporate knowledge conversion model into the e-education process

Figure 1 represents the knowledge management phases with e-Learning enhancements. In Figure 1, a Knowledge Holder can either transfer tacit knowledge to a Knowledge Seeker through socialization or create explicit knowledge and store it in a knowledge repository. The Knowledge Organizer in Figure 1 is a person (or software program) who relates the created knowledge to other knowledge in the repository or further refines the created knowledge. The Instructional Designer is a person (or software program) who organizes the learning of the knowledge by adding pre-assessments, additional learning aids, and post-assessments. The Knowledge Seeker then learns the explicit knowledge through an online guided learning experience. The Knowledge Seeker then uses the knowledge gained through socialization or internalization to make decisions and perform tasks in the enterprise. The performance of the Knowledge Seeker on these decisions and tasks is measured and returned to the knowledge repository as feedback that can be used to help determine if the skills have been learned and to suggest additional e-Learning experiences.[2,4]

\subsection{Apply Knowledge Tools and Techniques into E-education}

In the four steps of knowledge translation, every process has the relevant information technology tools to support it. In the process of socialization, there are video meeting tools, network camera tools and virtual reality tools; in the process of combination, there are systematic knowledge tools, collaborative tools, intranet, groupware, forum and practical databases; in the process of externalization, there are peer-to-peer networks, expert system, data mining tools, intelligence agency and chat platforms; in the process of internalization, there are Notes databases, pattern recognition and neural network. Apply the knowledge tools into e-education can not only help the learners manage explicit knowledge, but also can lighten the pressure of time and space. For example, intranet and collaborative groupware can promote the acquisition and communication of knowledge in online learning communities; video meeting and chat rooms permit the learners to discuss simultaneously by interactive media. All of them can lighten the evidence of learners and conscious of identity, in order to create a more suitable e-education environment.

\subsection{Use the theory of KM to Guide E-education Resource Management}

E-education resources libraries include media library, exercise problem library, test paper library, instructional case library, literature library and Q\&A library and so on. Education resource management includes index, check and retrieve. [3] Because resource repository is a kind of knowledge repository, a refined knowledge repository, we can use the theory of KM to guide the management of e-education resource management. In the process of resource management, we should consider what kind of resource can be stored in the library, how to access and organize the resources. $[5,6]$ According to the concepts of $\mathrm{KM}$, firstly we must understand the framework of education resources and the tools to evaluate and control the resources; 
secondly we must master the structure and component of the repository and know how to monitor the behaviors of the learners. We designed a resource management framework, the framework divided into six steps $[7,8]$, see figure 2:

Step 1: confirm the learners' request from the aspects of subject, search context, the type of resources, resource type and so on.

Step2: collect the learners' profiles, including their main interest, mater degree of knowledge, the expected status and learning styles.

Step 3: synthesis the learners' request and profiles.

Step 4: acquire the search results from local resource repositories, if the local resources can't satisfy the learner's request, start the global search mechanism to search more resources base on the user's restrict request.

Step 5: as soon as we have find the relative resource, we need to check and examine the resource. Subject expert system can pick up the expert knowledge to check the resource [8].

Step 6: the resources passed examination are organized and categorized again, then we store them into the local resource repository and provide the learner, they can also be used by other learners.

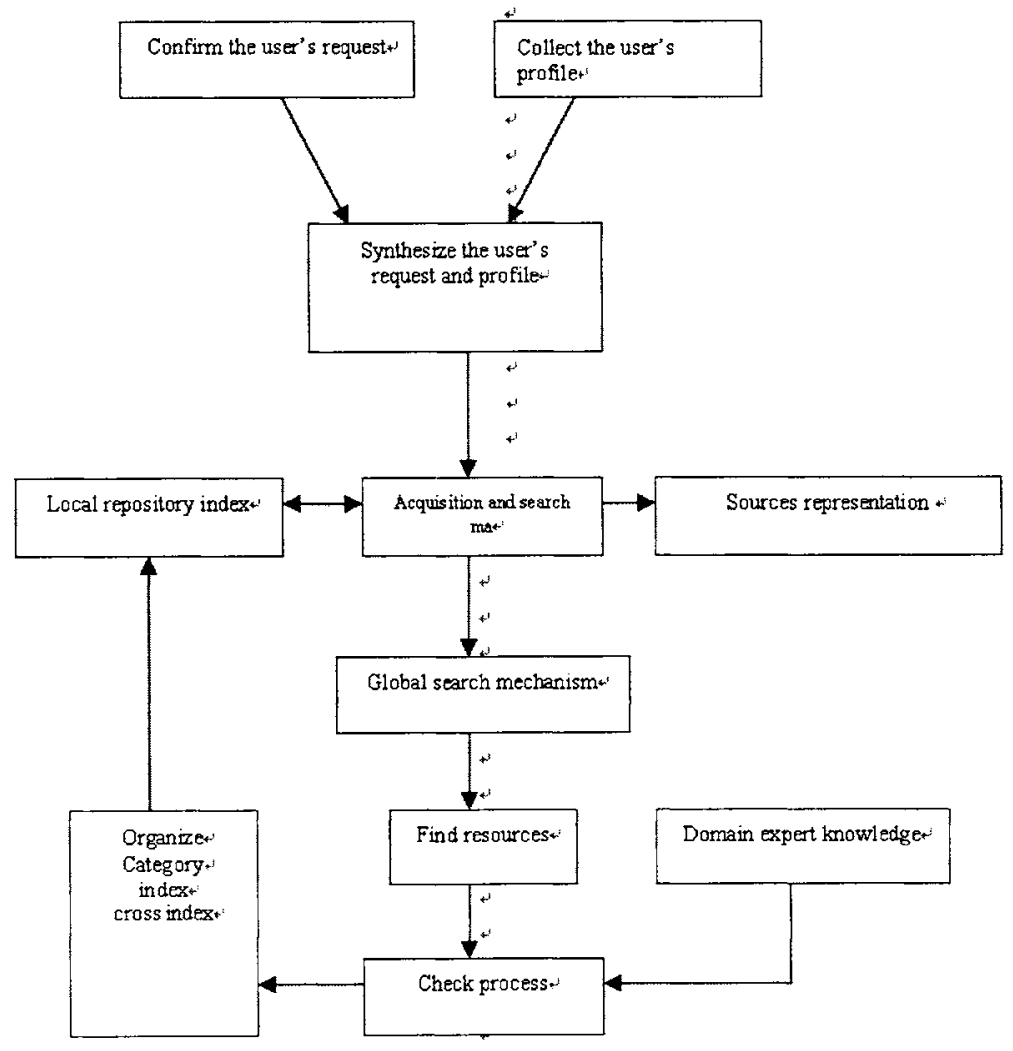


Fig. 2.The e-education resource management framework using knowledge management theory

\section{Conclusions}

Most organizations realize that "knowledge" is a strategic resource that gives them sustainable competitive advantage and helps them achieve long-term organizational goals. With the realization that knowledge is a core resource, organizations are now attempting to manage knowledge in a more systematic and more effective way. However, managing knowledge is not always an easy task. $[6,9,10]$ In particular contexts, such as online e-education, knowledge is distributed across both time and space and may be constrained by social, cultural and language differences. This paper demonstrated the common characters of $\mathrm{KM}$ and e-education, and proposed the current potential problems in e-education the authors tried to develop a set of guidelines to help overcome problems using tools and techniques from $\mathrm{KM}$. We proposed three strategies: corporate explicit knowledge and tacit knowledge; Use the theory of KM to guide e-education resource management; Use the theory of KM to guide e-education resource management. These strategies will help us to develop a better e-education framework.

\section{References}

1. D.Woelk and S.Agarwal, Integration of e-Learning and Knowledge Management, http://dmc.ic2.org/publications/elearnkm.pdf.

2. A.N.Ubon and C.Kimble, Knowledge Management in Online Distance Education, Proceedings of Networked Learning 2002.

3. E.Ras, Integration of E-Learning and Knowledge Management - Barriers, Solutions and Future Issues, http://www easy-hub.org/stephan/ras-postlokmol05.pdf.

4. Y.Zhang and Z.Zhu, Research on knowledge management and e-learning resource repository, E-education Research. 2003,(5).

5. H.Yang and L.Wang, Design and implementation of instructional case knowledge management system, China e-education. 2004,(10).

6. J.Mason, From elearning to e-knowledge, .Knowledge management tools and techniques 2005.

7. B.Marshall and Y.Zhang, Convergence of knowledge management and e-learning: the getsmart experience, http://www. ai.bpa.arizona.edu/go/intranet/Publication/JCDL-2003Marshall.pdf.

8. A.Petrides, T.R.Nodine, Knowledge management in education: definition and landscape, http://www. iskme. org.

9. Y.N.Singh and S.N.Chabra, E-education and content development: an experience, http://home.iitk. ac.in/ ynsingh/papers/itedu.pdf.

10. J.J.Kidwell, M.V.Linde and S.L.Johnson, Applying corporate knowledge management practices in higher education, Educause quarterly,2000 (4),pp.28-33 